\title{
Contracampo
}

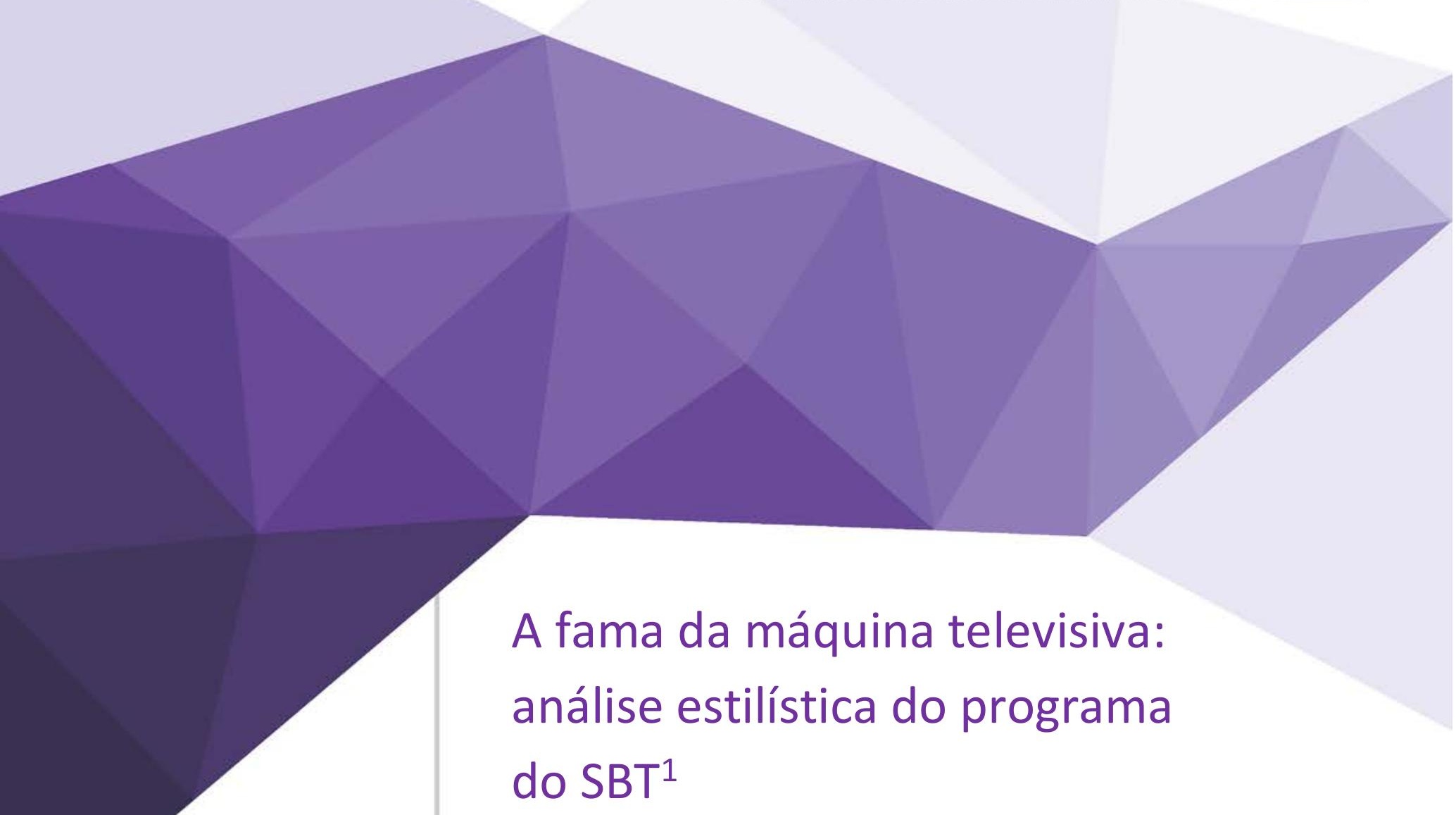

\section{The fame of the tv machine:}

stylistic analysis of the SBT's

Edição v.36

número 2 / 2017

Contracampo e-ISSN 2238-2577

Niterói (RJ), 36 (1)

ago/2017-nov/2017

A Revista Contracampo é uma revista eletrônica do Programa de Pós-Graduação em Comunicação da Universidade Federal Fluminense e tem como objetivo contribuir para a reflexão crítica em torno do campo midiático, atuando como espaço de circulação da pesquisa e do pensamento acadêmico.

\section{show}

\section{JOÃO PAULO HERGESEL}

Doutorando em Comunicação pela Universidade Anhembi Morumbi (UAM) e bolsista da Coordenação de Aperfeiçoamento de Pessoal de Nível Superior (PROSUP/Capes). Membro dos Grupos de Pesquisa Inovações e Rupturas na Ficção Televisiva Brasileira (UAM/CNPq) e Narrativas Midiáticas (Uniso/CNPq). Brasil. E-mail: jp_hergesel@hotmail.com

\section{ROGÉRIO FERRARAZ}

Doutor em Comunicação e Semiótica (PUC-SP), mestre em Multimeios (Unicamp) e graduado em Jornalismo (UNESP-Bauru). Foi pesquisador visitante na UCLA Los Angeles, com bolsa de doutorado-sanduíche (Capes). É professor do Programa de Pós-Graduação em Comunicação da Universidade Anhembi Morumbi (UAM). Brasil. E-mail: rferraraz@anhembi.br

\section{PPG COM armede UFF}

\section{AO CITAR ESTE ARTIGO, UTILIZE A SEGUINTE REFERÊNCIA:}

HERGESEL, J oão Paulo; FERRARAZ, Rogério. A fama da máquina televisiva: análise estilística do programa do SBT.

Contracampo, Niterói, v. 36, n. 02, pp. 81-99, ago. 2017/ nov. 2017 


\section{Resumo $^{1}$}

O Máquina da Fama é um programa de auditório que consiste na competição entre covers e na transformação de artistas convidados em fenômenos do cenário musical. Fechando o ano de 2015 na vice-liderança em audiência e iniciando 2016 com constantes vitórias sobre Xuxa, o formato é responsável por momentos marcantes na história contemporânea do SBT. Levando isso em consideração, questionou-se como os recursos expressivos utilizados por essa narrativa sugerem atingir a sensibilidade do telespectador. Para tentar responder a essa indagação, analisou-se um trecho do programa em que a apresentadora Patrícia Abravanel estabelece diálogo com ela própria, como se fossem personalidades distintas, antes de executar a tarefa de imitar a cantora Beyoncé.

\section{Palavras-chave}

Audiovisual; Televisão; SBT; Narrativas midiáticas; Estilística.

\section{Abstract}

Máquina da Fama (Fame Machine) is a reality show about the competition between artists performing cover versions and the transformation of guest artists onto music scene phenomena. By the end of 2015 the show was the second most seen by the audience and in the beginning of 2016 it beat Xuxa's TV show several times. The format is responsible for notable moments in TV channel SBT's contemporary history. As Máquina da Fama has become a hit on Brazilian television, this research sought to understand how the expressive resources used by this narrative appeal to the sensibility of the viewer. To answer that question the paper analyzes one episode in which the hostess Patrícia Abravanel establishes dialogue with herself, as if they were distinct personalities, before performing Beyoncé

\section{Keywords}

Audiovisual; Television; SBT; Media Narratives; Stylistics

\footnotetext{
1 Uma versão prévia deste artigo foi apresentada no Grupo de Trabalho Comunicação, consumo e identidade: materialidades, atribuição de sentidos e representações midiáticas, do 6. Encontro de GTs Comunicon, realizado de 13 a 15 de outubro de 2016, e publicada nos anais do evento sob o título "Entra a filha do Silvio Santos e volta a Patrícia Abravanel: estripulias expressivas no programa do SBT Máquina da Fama".
} 


\section{Considerações Iniciais}

Toda noite de segunda-feira, pouco depois das 23 horas, a tela do SBT se despede da bagunça liderada por Ratinho, na atração diária que leva seu nome, e se preenche com o roxo e o rosa-choque de visualidade multicromática, além de batida rápida e ritmada de sonoridade festiva. Trata-se do Máquina da Fama, programa de auditório apresentado por Patrícia Abravanel e dirigido por Michael Ukstin desde 2013, que compreende uma competição entre anônimos que são transformados em covers de seus ídolos.

Cada participante se apresenta, inicialmente, como pessoa não midiática e, após passar por um tratamento de maquiagem, cabelo, voz e coreografia, interpreta o artista escolhido, em cenário exclusivamente montado para tal. Até 2016, plateia era responsável por escolher as melhores performances da noite, premiadas com valores que vão de $R \$ 2$ mil a $R \$ 5$ mil. Em 2017, o programa sofreu leves alterações, deixando de lado a votação e as premiações e priorizando as apresentações musicais independentemente de avaliação crítica.

É relevante ressaltar que o Máquina da Fama se derivou da versão brasileira de My Name Is, produto criado pela FremantleMedia e que recebeu o nome no Brasil de Famoso Quem?2 ${ }^{2}$ O programa, formado por um repórter e três jurados, além dos preparadores artísticos, era veiculado nas noites de sábado e oscilava entre 4 e 5 pontos de audiência - abaixo da expectativa da direção artística da emissora (SANTO, 2013, [e]) - durante os quase dois meses em que ficou no ar.

Diante da constatação de que o estranhamento foi causado por o formato original não conter as marcas de estilo da emissora (utiliza-se, aqui, o termo "emissora" desvinculado da ideia clássica de emissor/receptor, mas como um sinônimo para "estação de televisão", assim como "canal" e "grupo televisivo"), o SBT sugeriu modificações para a segunda temporada, as quais foram rejeitadas pela criadora do programa.

Com base nisso, o canal resolveu romper contrato e desenvolver sua própria competição de covers, trocando o repórter por uma apresentadora e os jurados por uma plateia - configurando, de fato, um programa de auditório, principal característica do SBT -, além de realocar o horário de exibição para as noites de segunda-feira. O resultado foi que, logo no primeiro mês, a audiência subiu para 7 pontos no IBOPE, contra apenas 4 da Rede Record (PORTAL, 2014 [e]).

\section{Foco e escopo}

\footnotetext{
${ }^{2}$ Famoso Quem?. SBT. Disponível em: <http://goo.gl/9dnEeH>. Acesso em: 15 fev. 2016.
} 
Como reality show, o Máquina da Fama une características da realidade com nuances do universo fictício; suas estruturas narrativas tendem a se movimentar para imprimir verdade, autenticidade e naturalidade no que é expresso. Enquanto formato televisivo e seu impacto sociocultural, Rocha (2009, p. 14) comenta que a televisão, na busca pela realidade do espectador, "vai simular o mundo vivido no mundo midiático e, se tudo der certo, a simulação conseguirá persuadi-lo de que entre ambos não há diferença".

Deriva-se, desse formato, o talent show, por meio do qual as pessoas do convívio cotidiano adentram a atmosfera midiática e se convertem em famosos por alguns minutos, exibindo parte de seu suposto talento artístico. Nesse gênero oriundo do reality, "o talento, no entanto, não é o único requisito analisado, elementos como carisma e uma história de superação podem garantir sobrevida na competição", como sugere Baptista (2014, p. 1)

Trazendo essa visão para os covers shows, subgênero de talent show no qual se enquadra o Máquina da Fama, a pessoa precisa convencer a plateia de que consegue construir a personalidade que se propôs a imitar. Isso ocorre porque, nesse tipo de programa, "ao reproduzir a música de seu ídolo almeja chegar a tal posição de astro", gerando o conceito de "proto-astro", segundo Novaes (2010, p. $6)$.

Novaes ainda propõe uma justificativa para o sucesso desse tipo de programa, tanto em sua produção (o fato de haver participantes dos mais diversos costumes) quanto em sua recepção. Para o autor (NOVAES, 2010, p. 10), "a visibilidade é o que garante o existir, para um sujeito diante outro sujeito, logo temos a necessidade da aparência sobre qualquer essência". Novaes (2010, p. 10) complementa que "o primordial para os candidatos, nessa busca pela visibilidade, [é] apenas a aparição no meio televisivo, sem nenhum conhecimento musical que extrapole as barreiras da imitação".

\section{Recorte eleito}

Além das apresentações com anônimos, no entanto, o programa também recebe artistas convidados, que participam de um quadro denominado Desafio da Máquina. Nele, o participante - geralmente, cantor conhecido nacionalmente ou alguma personalidade do elenco da própria emissora - gira uma roleta virtual para descobrir qual fenômeno do cenário musical terá de encenar. Em seguida, o participante dirige-se à Máquina e, no final do programa, retorna trajado e maquiado tal qual a celebridade que terá de performar e executa seu espetáculo em um cenário que imita o do videoclipe da canção apresentada. 
A Máquina é basicamente a personagem central da narrativa. Mesmo sendo um mecanismo que se assemelha a uma porta giratória e apenas leva o participante do palco para os bastidores, ela assume a função de ser a responsável pela transformação do anônimo em famoso. Seria como um portal mágico que, num giro de 360 graus, prepara uma megaprodução, tanto na pessoa como no cenário.

O sucesso do quadro pode ser percebido não apenas nos índices de audiência - após sua estreia, o programa, que vinha oscilando entre o segundo e o terceiro lugar, consolidou-se na vice-liderança e acumula vitórias consecutivas sobre o Xuxa Meneghel, da RecordTV (FERNANDES, 2016, [e]) - como também na TV on-line ${ }^{3}$. No canal oficial do Máquina da Fama no YouTube ${ }^{4}$, os quatro vídeos mais assistidos são do Desafio da Máquina, estando, em ordem de maiores visualizações: Chiquititas imitando Fifth Harmony5; Maisa Silva imitando Lady Gaga ${ }^{6}$; Carrossel imitando One Direction7; e Sophia Valverde imitando Dorothy d'O Mágico de $\mathrm{Oz}^{8}$.

Visto que os vídeos mais benquistos são aqueles em que os participantes pertencem ao elenco do SBT, propõe-se, neste trabalho, uma análise sobre o programa de 14 de dezembro de 2015, quando a própria apresentadora, após estabelecer um diálogo inicial com ela mesma, como se fossem personalidades distintas $^{9}$, executou a tarefa de imitar a cantora Beyoncé ${ }^{10}$. Considera-se, para isso, que o Máquina da Fama é um reality show, imerso no grupo dos talent shows, dentro do subgrupo dos covers shows.

\section{Objetivos e justificativa}

Não tendo como objetivo primário o de compreender os embates sociológicos que esse tipo de programa pode provocar, mas sim o de averiguar o

\footnotetext{
${ }^{3}$ Utiliza-se o termo "TV on-line" no sentido de "extensão de apenas uma emissora", isto é, "no sítio das emissoras off-line na internet, encontram-se basicamente imagens de arquivo dos programas, e, eventualmente, imagens de arquivo de vídeos relacionados feitos exclusivamente para exibição on-line [...] diferentemente da TV off-line (em que é preciso aguardar o início de um programa), na TV on-line o usuário é quem decide ao que quer assistir e quando e em qual sequência (a não ser quando, também mais raramente, a emissora oferece assistir a uma transmissão simultânea)" (KILPP, 2015, p. 2).

${ }_{4}$ Canal Máquina da Fama. YouTube. Disponível em: <https://goo.gl/dXuypj>. Acesso em: 15 fev. 2016.

${ }^{5}$ Máquina da Fama (29/06/15) - Meninas de Chiquititas cantam Fifth Harmony. YouTube. Disponível em: <https://goo.gl/jDSVN>. Acesso em: 15 fev. 2016.

6 Máquina da Fama (17/08/15) - Maisa Silva vira Lady Gaga no “Desafio". YouTube. Disponível em: <https://goo.gl/uiuszp>. Acesso em: 15 fev. 2016.

7 Máquina da Fama (06/07/15) - Desafio: Meninos de Carrossel cantam One Direction. YouTube. Disponível em: <https://goo.gl/uW2YOA>. Acesso em: 15 fev. 2016.

${ }^{8}$ Máquina da Fama (22/06/15) - Desafio: Sophia Valverde interpreta Dorothy. YouTube. Disponível em: <https://goo.gl/KfiUCr>. Acesso em: 15 fev. 2016.

${ }_{9}^{9}$ Máquina da Fama (14/12/15) - Patricia vira Beyoncé no Desafio da Máquina. YouTube. Disponível em: <https://goo.gl/IUK8Ut>. Acesso em: 15 fev. 2016.

10 Máquina da Fama (14/12/15) - Patricia recebe a própria Pati no Desafio. YouTube. Disponível em: <https://goo.gl/Ow7sLb>. Acesso em: 15 fev. 2016.
} 
que ocorre no intermeio que limita sua poética de sua estética, optou-se pela análise estilística como metodologia. Acredita-se que verificar as marcas de estilo, tanto em caráter sonoro como imagético, é fundamental para compreender parte do êxito do programa enquanto atração popular.

\section{Metodologia}

A estilística pode ser verificada por quatro grandes vertentes: a linguística (BALLY, 1909), a literária (SPITZER, 1968), a cinematográfica (BORDWELL, 2008) e a televisiva (BUTLER, 2010). Enquanto os estudos audiovisuais tendem a se voltar às duas últimas, as análises de comunicação verbal se utilizam das duas primeiras. Acredita-se, no entanto, que a televisão, por ser uma mídia que condensa, em suas linguagens sonora e visual, elementos das modalidades oral e escrita, uma combinação de todas essas subáreas é bem-vinda.

Para Charles Bally (1909), a estilística tem como objeto de investigação a afetividade manifestada por meio da linguagem e os elementos de linguagem manifestados por meio da afetividade. Para Leo Spitzer (1968), a estilística tem a missão de detectar os recursos utilizados nos textos que os fazem sobressair e atingir o estado de poético. Com o tempo, verificou-se que essas duas visões mais se aproximavam do que se distinguiam e passou-se a considerar a análise estilística um processo pelo qual se identifica aquilo que se destaca na linguagem para que se criem laços afetivos entre os interlocutores.

Para David Bordwell (2008), o estilo tende a ser a perceptividade de marcas características de um cineasta e/ou uma produtora com base nos elementos narrativos e de mise-en-scène que se repetem nas obras fílmicas. Para Jeremy Butler (2010), o estilo também é identificado pelas técnicas de produção e pela estética apresentada, mas considera também o contexto cultural da realização do produto e, portanto, as significações que ele pode apresentar. Outros autores que tomam por base essas definições encontram, entre elas, um grande paralelo, o que faz com que a metodologia adotada para o cinema coincida com os pressupostos metodológicos para televisão.

Neste estudo, o que se propõe é uma união entre as esferas apresentadas. Mesmo com ciência de que existem estudos pertinentes na área do estilo televisivo, encabeçadas por seguidores de Butler, verifica-se que eles se dedicam mais às séries televisivas norte-americanas e europeias do que às produções brasileiras. Ao investigar quais são os recursos expressivos que se manifestam tanto na camada sonoro-imagética como na retórico-discursiva, propõe-se entender um pouco mais como se molda o estilo em uma narrativa construída em um programa de auditório. 


\section{Análise estilística do Máquina da Fama}

Oferece-se, aqui, uma leitura da cena em que Patrícia Abravanel convida ela própria para subir ao palco e, diante de si enquanto outra, faz uma breve entrevista, fortalecendo a ideia de haver duas personalidades distintas: a apresentadora $(A)$ e a participante $(P)$. Tanto os registros visuais (técnicas utilizadas para enquadrar e estabelecer os cortes) como a sonoridade (representada pelo diálogo e pelas falas simultâneas) contribuem para personificar cada uma das Patrícias, chegando a confundir o telespectador mais desatento ${ }^{11}$.

Câmera alta. A apresentadora, de camisa e calça brancas brilhantes, está caminhando na passarela, dirigindo-se para o palco, com a plateia nas laterais. Dá meia volta. Mudança de câmera. Plano americano. Ela está com o olhar direcionado para a câmera, centralizada no plano e com luzes de holofote sendo lançadas atrás de seu corpo, do centro para as laterais do enquadramento. Enquanto fala, em companhia de uma sonorização de música latina, o gerador de caracteres mostra seu nome de usuário no Instagram e o logotipo da emissora, com a menção “closed caption" logo acima, em caixa-alta. ${ }^{12}$

Nesse início, a figura de Patrícia Abravanel é tratada como estrela (nos dois sentidos da palavra: tanto no de personalidade famosa como no de astro sideral). No momento em que anda sobre a passarela, ela é ovacionada de forma ritmada e incansável pelas pessoas do auditório. Também é observável certa alusão da cor de sua roupa perolada à luz emitida pelas constelações, além da iluminação em faixas, ao fundo, remetendo às pontas de uma estrela real.

A música latina ${ }^{13}$ sugere a atmosfera de alegria do programa, um fenômeno característico do $\mathrm{SBT}^{14}$. E a combinação de todos esses elementos descritos demonstra que "as qualidades expressivas podem ser transmitidas pela iluminação, pela cor, pela interpretação, pela trilha musical e por certos movimentos de câmera" (BORDWELL, 2008, p. 59), como é perceptível nos demais momentos ao longo desta análise.

\footnotetext{
${ }^{11}$ Na página do vídeo no YouTube, existem diversos comentários de usuários se perguntando quem seria a atriz que interpretou a segunda Patrícia ou até mesmo se questionando se a apresentadora teria uma irmã gêmea. Neste trabalho, optou-se por desconsiderar a discussão acerca da troca de informações realizadas na página virtual, uma vez que tal proposta desviaria o foco desta pesquisa.

12 Para mencionar os tipos de plano, adotou-se a nomenclatura apresentada por Francis Vanoye e Anne Goliot-Lété (2002).

${ }^{13}$ A trilha sonora, de certa forma, contribui "para que o Brasil se reconheça e se aproxime cada vez mais da América Latina de língua hispânica, cujas matrizes históricas e culturais, conflitos sociais e políticos, formam um terreno comum de vivências e compartilhamentos" (ROCHA, 2016, p. 11).

14 "[...] a alegria se mostra como um sentimento chave na relação de mútua dedicação: o SBT sente-se alegre em poder compartilhar sua programação com o telespectador, que, por sua vez, também sente alegria ao se ver no SBT e fazer parte dessa família" (MARTINS, 2014, p. 14).
} 
A: E esse mês de dezembro continua superespecial. Tá vindo aí uma artista que eu conheço ela há muito tempo. Ela é da família e já esteve várias vezes aqui no nosso palco. Com vocês, Patrícia Abravanel!

Há uma demarcação de tempo/espaço e também de afinidade. Primeiramente, é ressaltado que a exibição do programa ocorreu no mês de dezembro, o que prejudicaria reprises em outro mês, fato recorrente na emissora. Em seguida, antes de mencionar o nome do participante, cria-se um vínculo de afetividade e autoexaltação, destacando que, além de ser "da família", isto é, alguém próximo da apresentadora, ainda é "artista" e "já esteve várias vezes no palco". O pensamento do telespectador tende a se limitar: dos artistas da família Abravanel, ela é a única que marca presença semanalmente no programa.

A adivinha desenvolvida para quem está assistindo (e não consultou previamente as chamadas do programa ou a sinopse de seu conteúdo) é, portanto, facilmente solucionada. Ao pronunciar o próprio nome, no entanto, espera-se gerar um gatilho para o sentimento de surpresa: afinal, como ela entraria na mise-enscène, se ela já está em cena? O questionamento se soluciona apenas depois de um rápido flashback, retomando, em pequenos momentos, algumas apresentações artísticas de Patrícia.

Nesse momento, ocorre uma breve exibição de trechos de covers já realizados por Patrícia, iniciando em Whoopi Goldberg e passando por Carmen Miranda e Jennifer Lopez, em microexcertos sem o áudio da apresentação, seguido de fragmentos sonorizados de Carmen Miranda, Shakira, Jennifer Lopez e Pequena Sereia. Um foco de luz encerra o vídeo e a imagem da apresentadora é novamente visualizada.

A retomada de tais performances realizadas ao longo da carreira de Patrícia ajuda a endossar a ideia de ela ser uma "artista", uma estrela, alguém transformado pela Máquina, personagem fundamental dessa narrativa. Os telespectadores não assíduos tendem a assimilar a desenvoltura da apresentadora e seus aparentes multitalentos; já aos mais fiéis cabe relembrar cada um dos momentos e aproximar da ideia de Silvio Santos, ícone principal da estação, já ter elogiado o desenvolvimento da filha enquanto fenômeno midiático ${ }^{15}$.

A: E pode entrar, Patrícia.

\footnotetext{
${ }_{15}$ Mais pai do que apresentador, Silvio usa Teleton para promover Patrícia. Blog do Maurício Stycer, 25 de outubro de 2015. Disponível em: <http://goo.gl/oYUeLg>. Acesso em: 15 fev. 2016.
} 
Mudança de câmera. Câmera alta. Patrícia entra com camiseta vermelha e calça azul, também sob aplausos da plateia. A partir desse momento, ocorre a alternância de câmeras: ora, a apresentadora é posicionada em plano americano; ora a participante é registrada, também nesse tipo de plano; ora as duas são enquadradas em plano conjunto. Os holofotes projetam inúmeras estrelas no chão do palco.

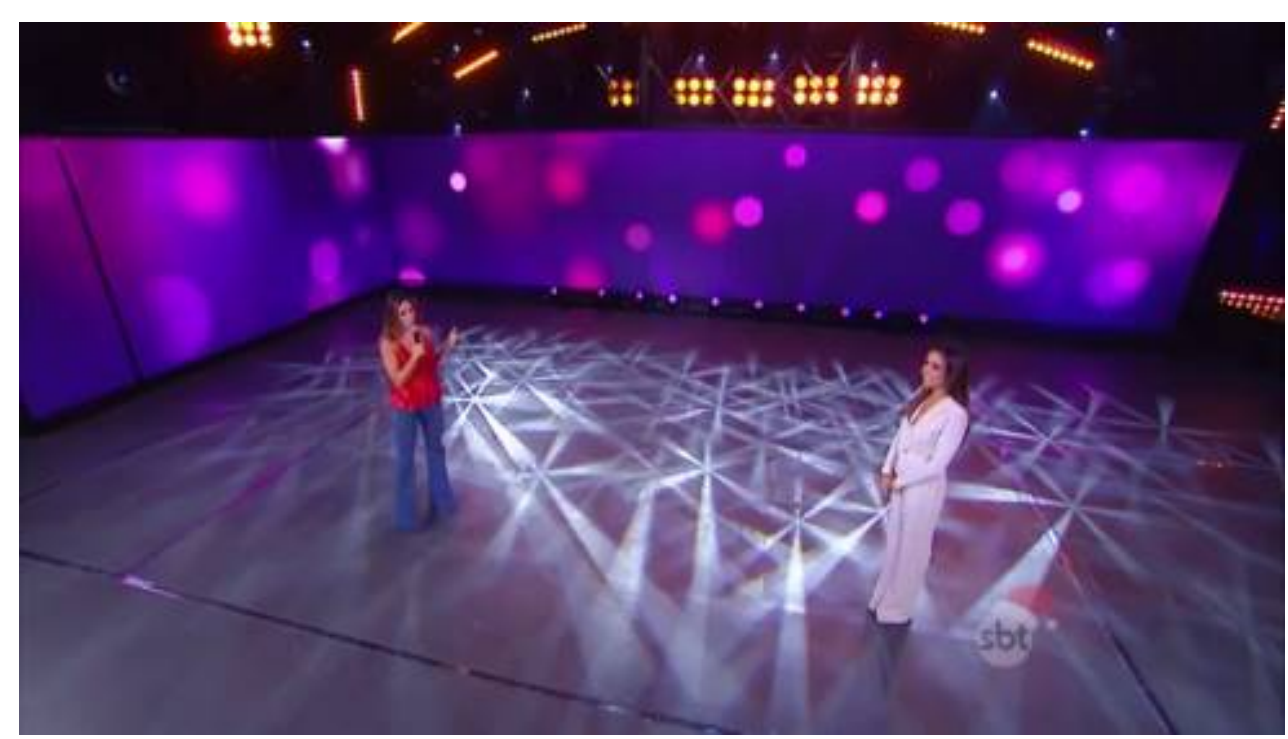

Figura 1 - Patrícia (apresentadora) e Patrícia (participante) dividem o mesmo palco. Fonte: Registro via print screen do vídeo do programa.

Torna-se evidente que, embora o percurso realizado pela participante tenha sido o mesmo que a apresentadora tomou alguns segundos antes, a que acabou de entrar ainda não está pronta para ser considerada famosa. Suas roupas cotidianas e visual básico, sem muita maquiagem ou penteado caprichado, levam a crer que será necessária a ajuda da Máquina para que ela se prepare e brilhe no palco. 0 figurino e a maquiagem, recursos apontados por Bordwell (2008) como alguns dos denotadores de estilo, mostram-se fundamentais para o funcionamento desse programa.

\section{A: Ê, Patrícia! Finalmente você veio.}

Nessa fala, a apresentadora distorce a ideia sugerida inicialmente: a de que está toda noite de segunda-feira à frente do programa e, com isso, sendo admirada por meio desse canal. O efeito provocado é de que a participante, enquanto pessoa distinta da apresentadora, já havia sido convidada outras vezes para estar ali (não necessariamente pela primeira vez, visto o que foi mencionado anteriormente, mas como uma visita que faz bastante tempo que não aparece), mas só então resolveu aceitar. 
P: Boa noite, Patrícia. Boa noite, pessoal de casa. Eu tô feliz de tá aqui.

A partir daqui, não existem apenas dois interagentes; o público que assiste pela televisão se torna o terceiro participante do diálogo, um personagem coletivo, ainda que não venha a interagir ou modificar o trajeto previsto para a narrativa. Ao cumprimentar o telespectador, a participante cria um vínculo não apenas com a apresentadora à sua frente, mas com todos que estão atentos à sua fala. Em outras palavras, cria-se um convite para o público participar da obra, outra particularidade comum nos programas de auditório do SBT, incentivada por Silvio Santos ${ }^{16}$.

A partir de uma perspectiva que se aproxima dos estudos de Bordwell (2008), pode-se inferir que a tendência é que o espectador se concentre nos rostos dos personagens em cena, nos diálogos que vão se construindo e nos gestos que são executados, atentando-se em como esses elementos se justificam para o desenrolar da narrativa. Os rostos e os corpos que os completam, as palavras e os efeitos que elas produzem, os gestos e a coreografia a que obedecem, tudo propõe uma abordagem ora informativa, ora apenas encantadora, criando laços afetivos com a audiência sem que esta tenha plena consciência do que ocorre.

\section{A: Como você se descobriu cantora?}

Inexiste a possibilidade de ela não ser cantora; a função é automaticamente designada a ela. Mesmo assim, o ato de cantar não é proposto como dom congênito, nem como resultado de um esforço contínuo, mas como descoberta derivada de uma experiência.

P: Foi aqui que eu me descobri cantora. (Risos.) Na verdade, teve uma vez que eu fui lá atrás, na Mara Maravilha, que eu acho que eu tinha muita vontade de cantar. E daí eu fui lá, e 'ranquei o microfone da mão dela, e dancei pra caramba. Acho que ali já tinha uma coisa assim de eu querer se cantora.

Ao indicar o local em que a função de cantora lhe foi outorgada, Patrícia assume que participar do Máquina da Fama é um processo para qualquer pessoa manifestar seu talento. Ainda na fala, ela relembra seu passado, já conhecido pelos

\footnotetext{
${ }^{16}$ Nos programas de auditório do SBT, a personalidade que está em cena “[...] dirige-se diretamente ao público que assiste ao vivo e, ao se posicionar em frente à câmera, ao telespectador que está em casa. Dialogar é, então, uma qualidade essencial a esse gênero, ajudando a fazê-lo ser reconhecido como tal" (SOUSA, 2011, p. 35).
} 
fãs, quando saiu do auditório do Show Maravilha ${ }^{17}$ e invadiu o palco, ganhando atenção das câmeras e dividindo o destaque. Seu entusiasmo é percebido pelo polissíndeto ${ }^{18}$ adotado, além de a coloquialidade - registrada, sobretudo, com uma aférese $^{19}$ - a aproximar de um nível de linguagem popular, outro elemento que permeia o $\mathrm{SBT}^{20}$.

(A apresentadora acena com a cabeça, sorrindo, como que consentindo em tempo real o que a participante comunica.)

P: Daí na hora que me deram um programa assim... (Chacoalha a mão, para os lados, como que indicando a proximidade com a apresentadora.) Cê sabe, né? Tipo Máquina da Fama. Aí eu me realizei, era tipo coisa de infância. (Risos.)
A: E até hoje foram quantos shows?
P: Foram vários shows. Foram... O primeiro que eu fiz foi o da Carmen Miranda, foi sensacional. Shakira. Foi Frozen, depois foi Ivete. Depois foi a Whoopi, que foi superdivertido. A J-Lo, megaprodução, máximo. Aí foi a Xuxa. Aí começou aquela coisa assim, de eu voltar à infância. Xuxa, Pequena Sereia, e aí depois... Eu tô aqui hoje.

( $O$ auditório aplaude.)

É visível que, enquanto a apresentadora assume uma postura mais formal, com frases curtas e dentro da norma-padrão da Língua Portuguesa, a participante demonstra-se mais solta, expressando-se em nível coloquial. A quebra de paralelismo ${ }^{21}$ na oratória da participante é a maior representação de seu estilo popular, levando a crer na inexistência de um roteiro - o que fez com que ela tivesse de responder às perguntas com base na espontaneidade e no improviso ou, até mesmo, de um roteiro pautado nesse cuidado estilístico. A ovação da plateia corrobora a aceitação do público.

\footnotetext{
17 Show Maravilha foi um programa infantil apresentado por Mara Maravilha e exibido pelo SBT no final dos anos 1980. A participação de Patrícia Abravanel, ainda criança, ocorreu em 1987, segundo informações do arquivo do SBT. Verificar vídeo em: "Cante Se Puder - Patrícia Abravanel relembra sua participação no programa da Mara". YouTube. Disponível em: <https://goo.gl/C1786h>. Acesso em: 15 fev. 2016

18 Polissíndeto é a figura de construção que consiste repetição de uma conjunção coordenativa no início de cada oração e que tende a resultar numa "sugestão de movimentos, estados ou ações que se sucedem rápida ou ritmicamente" (HENRIQUES, 2011, p. 114). No caso, tem-se a repetição constante do "e".

${ }_{19}$ Aférese é a figura de harmonia, também considerada um "metaplasmo", gerada pela "supressão de fonema ou sílaba no início de palavra" (MONTEIRO, 2005, p. 64). No caso, tem-se o neologismo "ranquei".

20 "O SBT, fundado sobre um conceito de popularidade, apropria-se categoricamente desse estilo neotelevisivo [...] O SBT é um canal que espelha o cidadão comum e se apoia na estratégia de identificação e aproximação com o público" (SOUSA, 2011, p. 46).

${ }^{21}$ Paralelismo "é a repetição de ideias mediante expressões aproximadas" (BECHARA, 2009, p. 644). No caso, Patrícia não segue uma mesma estrutura em suas frases: enquanto algumas são completas, formadas por adjetivação e explicações mais aprofundadas, outras se limitam apenas a mencionar o nome da pessoa imitada, seguido ou não de um verbo de ligação.
} 
A: Me fala qual desses você gostou mais.

P: Todos tiveram uma coisa diferente. Eu amei fazer Xuxa. (Exibe-se um trecho mudo da apresentação, em concomitância à fala dela.) Eu acho que realizei o sonho de várias pessoas na hora em que eu desci daquela nave lá, sensacional. (Exibe-se um trecho da apresentação como J-Lo.) Amei J-Lo, ficou lindo. (Exibe-se um trecho da apresentação como Shakira.) Shakira, que eu dancei. Ai, todos tiveram um... (Volta para Patrícia no palco.) Um sabor assim, bem gostoso. Eu amei fazer... Eu amo... Por mim, eu apresentava toda semana aqui.

Percebe-se que, ao interrogar a participante a respeito de seus shows anteriores, a apresentadora abre espaço para retomar, novamente, as performances de Patrícia, inicialmente exibidas em tentativa de analepse ${ }^{22}$. Essa constante aparição das realizações reforçam a ideia de que a participante fez um trabalho admirável em edições anteriores e poderá repetir no êxito no desafio presente. Tal sentido é resgatado na fala seguinte da apresentadora.

A: Bom, já deu pra perceber que você é corajosa. (Direciona o olhar para a câmera.) Mas será que ela tá preparada pra encarar o Desafio da Máquina? Vamos ver!

(Exibe-se a vinheta do Desafio da Máquina.)

O layout utilizado para ilustrar o quadro é semelhante à adotada pelo SBT nos sorteios do consagrado Pião da Casa Própria ${ }^{23}$, que se acoplou à imagem de Silvio Santos. Nota-se que a constituição do círculo fatiado é distinta: enquanto o Pião é envolto por um painel de madeira que lembra a imagem das pétalas de uma flor, a Máquina é formada por faixas de luzes que partem do centro e se destinam às bordas. Ainda assim, é importante observar a possível intenção de associar à imagem da filha a forma vinculada, por tantos anos, à imagem do pai ${ }^{24}$.

\footnotetext{
${ }^{22}$ Analepse é a figura de construção que, mais conhecida como retrocesso ou flashback, é “um recuo na linha do tempo a um evento que ocorreu anterior ao tempo do discurso" (HERGESEL, 2015, p. 60).

${ }^{23}$ O Pião da Casa Própria, ou Pião do Baú, ou ainda Pião da Felicidade foi um objeto cenográfico do programa Festival da Casa Própria, a partir de 1986, e que consistia em dar prêmios ao participante que obtivesse números iguais ou maior número após girá-lo. De 1994 a 2002 e de 2007 a 2009, o Pião ganhou um quadro no Programa Tentação. Posteriormente, o Pião integrou o programa Pra Ganhar É Só Rodar. Após um período fora do ar, o programa voltou à grade da emissora em 2016, reformulado e exibido nas noites de quarta-feira.

${ }^{24}$ Aqui, a análise estilística incorpora a segunda dimensão proposta por Butler (2010), retomada por Rocha (2016, p. 31), de examinar o funcionamento do estilo dentro do sistema textual.
} 


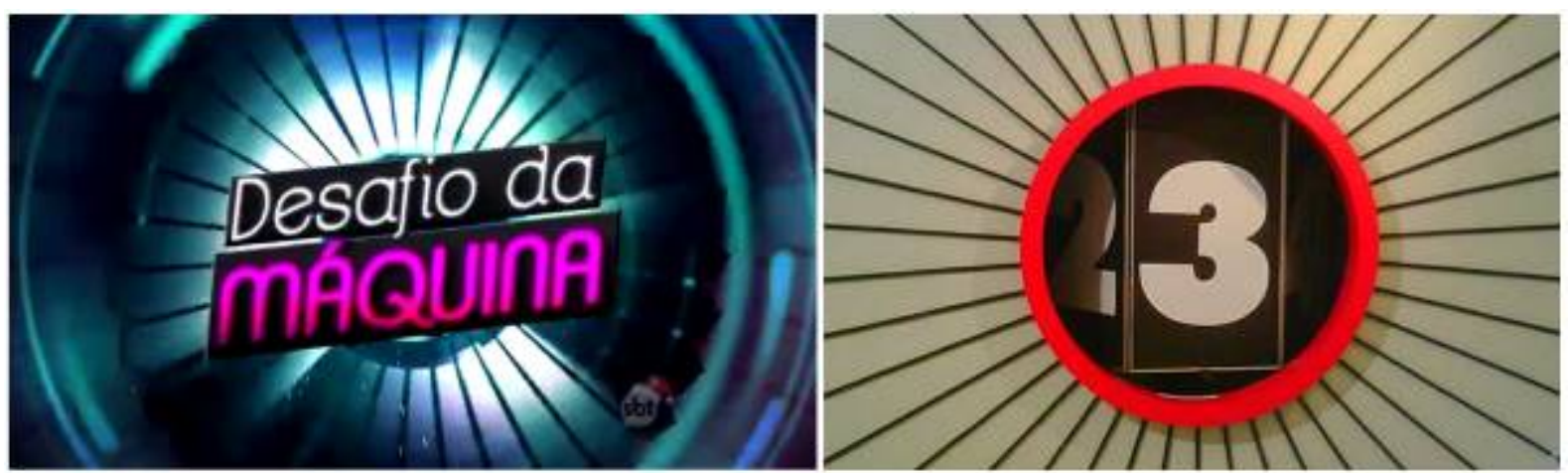

Figura 2 - Comparação entre o design do Desafio da Máquina e o do Pião da Casa Própria. Fonte: Registro via print screen de vídeos dos programas.

A: Vamos lá, girando a roleta, então, para o Desafio da Máquina da Patrícia. Vamos ver quem tá aí pra você. É uma diva, mas qual diva?

(A roleta começa a girar. Todas as imagens são da Beyoncé.)

A roleta, peça central do Desafio da Máquina, que indicará o artista que deverá ser imitado, é notavelmente uma versão digital do icônico Pião. O inusitado, no entanto, está no fato de todas as imagens, nesse programa com a Patrícia, serem de uma única celebridade: Beyoncé. Não há, portanto, possibilidade de outro artista ser escolhido; ainda assim, ocorre uma euforia por parte da participante, que torce para a roleta parar em Beyoncé e, quando consumado o fato, comemora festivamente.

Como apontado, o diálogo não cessa enquanto a roleta gira; a linguagem sonora, sobretudo verbal, adquire uma forte significância para a narrativa. Esse fenômeno retoma, de certa forma, a ideia registrada por Simone Maria Rocha (2016, p. 48) de que "a experiência de assistir [à] televisão é igualmente uma experiência de ouvir televisão". Além disso, privilegiar o som é uma estratégia para garantir a manutenção da atenção do espectador e, consequentemente, do sentido daquilo que se cria na tela. Ao enfatizar o som, o produto televisivo preenche a lacuna deixada pela imagem carente, a fim de evitar a redução de seu valor transformador.

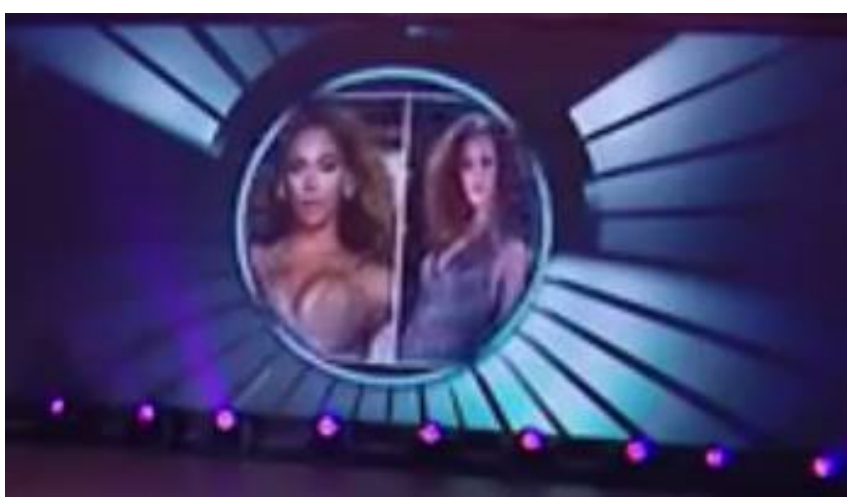


Figura 3 - Roleta do Desafio da Máquina.

Fonte: Registro via print screen do vídeo do programa.

P: Beyoncé! Beyoncé!

A: Beyoncé!

P: Diva, diva, diva... Muitas divas! Uhul! Beyoncé! Beyoncé!

A: É tudo Beyoncé?

P: Que isso, meu Deus do céu!

A: Não é possível. Tem esquema com a produção. (Direciona o olhar para a participante.) Você pediu Beyoncé? (A fala ocorre enquanto a participante continua gritando: "Beyoncé! Beyoncé! Muitas divas...".)

P: Beyoncé!

A: Não é possível.

P: Olha que linda. Olha como ela tá linda.

A: Ela ali também é a Beyoncé!

P: Diva máster! Diva mega!

A: Gente, como ela se transforma. Tem várias versões de Beyoncé aqui.

(A roleta para.)

P: Beyoncé! (Interjeição festiva alongada.)

Em questão de segundos, a palavra "Beyoncé" é mencionada, pelo menos, doze vezes. A epanode ${ }^{25}$ gerada pela repetição incessante do nome da artista e a epizeuxe ${ }^{26}$ da adjetivação "diva" frisam a ideia de que a participante é uma grande fã da cantora norte-americana e que fazer seu cover será uma forma de se transformar em alguém ainda mais glamorosa. Trata-se, portanto, de uma homenagem, mais do que um desafio ou uma competição.

Vale ressaltar que a figura de Beyoncé é evidenciada, sobretudo em assuntos acadêmicos, uma vez que ela representa o empoderamento da mulher afrodescendente e a luta contra o preconceito racial. Como pontua Mateus (2016, p. 14), "a partir do momento em que ela [Beyoncé], como mulher negra, toma para si um discurso identitário, as arestas do racismo institucional se tornam mais evidentes". A força imagética da personalidade é um elemento-chave para justificar a euforia de Patrícia.

A: Parabéns! Beyoncé. Eu só tô impressionada que cê deve ter... Ela deve ter esquema, não é possível, com a produção. Só tem Beyoncé aí. Agora, será que

\footnotetext{
${ }^{25}$ Figura de construção que "se presta à exploração cômica, retórica ou lírica pelo seu caráter obsessivo [...], consiste em repetir sem cessar uma palavra" (SUHAMY, 1994, p. 70).

${ }^{26}$ Figura de construção que "se caracteriza pela repetição seguida do vocábulo" (HENRIQUES, 2011, p. 141).
} 
tem esquema também no show do Desafio? Vamos ver qual é o Desafio que a Máquina preparou para você.

(Exibe-se um trecho do clipe que deverá ser imitado.)

P: Muito, muito difícil. Mas eu amo desafio. Eu tava louca pra fazer uma diva, eu tava louca pra fazer a Beyoncé e eu acho que ninguém acredita que eu dou conta do recado, nem eu mesma acredito.

( $A$ apresentadora sorri.)

P: Mas eu tô muito querendo ver se eu encaro. E eu tava conversando com o pessoal lá atrás, a Lu, que ela faz os ensaios, ela falou que a mulher muda depois que faz Beyoncé, fica mais... (Mostra, com a mão, seu corpo de cima a baixo.) Entendeu?

Sustentando a brincadeira de a participante não ser a mesma pessoa que a apresentadora, esta insinua que aquela negociou com a produção antes de girar a roleta. E mantendo a postura de surpresa por supostamente não saber que faria um cover da Beyoncé, a participante relata quão difícil será o desafio e, em anáforas ${ }^{27}$ que destinam à restrição (de todas as divas, a Beyoncé; de todas as pessoas, ela própria), desabafa sua vontade de interpretar a cantora.

A comunicação imagética tem sua relevância amplificada nesse ponto. À medida que a comunicação sonora vem se centrando quase que totalmente na linguagem verbal, a visualidade oferece complemento indispensável à mensagem, sobretudo em dois momentos. O primeiro é a insistência de enquadrar a apresentadora consentindo calada com o que a participante fala, resgatando a ideia de conversa em tempo real e da existência de duas pessoas diferentes; o segundo é o gesto que a participante faz para informar, em elipse ${ }^{28}$ verbal, que interpretar Beyoncé deixa as mulheres mais seguras e atraentes.

A: Dá pra falar que esse vai ser um desafio... vai ser um dos desafios mais ousados da sua carreira. Cê tem que segurar figurino, aquele cabelo, fazer carão... Cê acha que cê vai conseguir mesmo?

P: Com certeza! Não tenho nem dúvida. Não sei nem se eu consigo fazer, mas eu tô aqui. Vamos lá. Que medo.

\footnotetext{
27 Figura de palavra (tropo) que "consiste em começar vários versos, frases ou partes de frases sucessivas pela mesma palavra ou grupo de palavras" (SUHAMY, 1994, p. 72).

${ }^{28}$ Figura de construção em que "a palavra subentendida não foi empregada anteriormente, pois sua presença é percebida com nitidez no contexto ou situação" (HENRIQUES, 2011, p. 147).
} 
A apresentadora se utiliza de uma gradação em clímax ${ }^{29}$ para intensificar a dificuldade de fazer uma imitação de Beyoncé, cantando e dançando simultaneamente. A hipérbole ${ }^{30}$ gerada pela pergunta deixa a participante em conflito, fazendo com que se expresse em paradoxo ${ }^{31}$ : logo após dizer que se considera capaz de se transformar em Beyoncé e realizar um espetáculo no palco, mostra-se insegura e assume que não tem certeza de que conseguirá executar a tarefa com sucesso; reconhece que é o momento de encarar, mas confessa estar medrosa.

A: Patrícia... (Chacoalha o dedo para diante de si, como que indicando a proximidade das duas Patrícias.) Te conheço, Patrícia. (Pausa.) Sei não, cê tá pronta?

P: Acho que sim.

A: Então, entra na Máquina a Patrícia Abravanel, a filha do Silvio, e volta diva e poderosa, como a estrela do pop, Beyoncé.

(A participante se dirige para a Máquina, enquanto o auditório aplaude.)

Patrícia Abravanel permanece com a estripulia expressiva de ser duas pessoas distintas, embora esclareça que conhece a outra como sendo ela mesma. A importância da Máquina - enquanto metonímia ${ }^{32}$ para se referir aos maquiadores, cabeleireiros, figurinistas, coreógrafos e preparadores vocais - para a transformação da participante é ressaltada pelo eufemismo ${ }^{33}$ seguido de hipérbole que trabalham juntos. Essa também é uma amostra de como as figuras de estilo, tão caras à linguagem verbal, podem se manifestar na imagem em movimento.

Ao intensificar a ideia de que Beyoncé é "diva e poderosa" e "estrela do pop" e deixar em contraponto a ideia de que Patrícia seria apenas "a filha do Silvio", como se essa antonomásia ${ }^{34}$ não caracterizasse uma personalidade midiática relevante, a apresentadora defende a ideia de que a produção do programa é responsável por transformar alguém que só está lá por ser parente do dono -

\footnotetext{
${ }^{29}$ Figura de pensamento que "caracteriza-se pela acumulação sucessiva de palavras ou expressões que intensificam progressiva(mente) [...] uma ideia" (HENRIQUES, 2011, p. 149).

${ }^{30}$ Figura de palavra (tropo) que "violenta a realidade, exagerando as ideias, não raro até o absurdo, sem que se encontre qualquer limite" (MARTINS, 2008, p. 265 - primeira edição em 2005).

31 Figura de pensamento na qual "conciliam-se duas ideias opostas de modo a contrariar o senso comum" (HENRIQUES, 2011, p. 149).

32 Figura de palavra (tropo) que se baseia "numa relação real e não mentada, portanto, não comparativa [...]; as relações reais de ordem qualitativa que levam a empregar [...] uma palavra por outra, a designar uma coisa com o nome de outra" (GARCIA, 2007, p. 114-115 - primeira edição em 1967).

33 Figura de pensamento entendida como "meios expressivos que adoçam a brutalidade ou a inconveniência social" de ideias (LAPA, 1998, p. 21 - primeira edição em 1982).

${ }^{34}$ Figura de palavra (tropo) que "consiste na substituição de um nome próprio por um nome comum [...] geralmente constituída por um agrupamento de palavras" (GARCIA, 2007, p. 121-122 - primeira edição em 1967). É uma derivação da metonímia.
} 
jargão que ela própria utiliza em participações no programa do pai - em uma artista multitalentosa.

Após a entrada da participante no que seria um portal especializado em modificações de personalidade, o programa prossegue com a participação de anônimos. Somente no último bloco da atração, quando do fechamento do programa, Patrícia volta transformada em Beyoncé e executa sua performance no palco, com cenário específico e bailarinos a auxiliando.

\section{Apontamentos finais}

A alegria é o sentimento predominante no Máquina da Fama, caracterizada pelos sorrisos, pela música festiva, pelo movimento da iluminação e, principalmente, pelo discurso verbal estabelecido no palco. A tentativa de levar o povo à TV é outro aspecto observável: cada uma das Patrícias representa um grupo - enquanto a participante veste-se e expressa-se de modo simples, tal qual o a maior parcela dos brasileiros, a apresentadora mantém uma postura mais culta e ética, ilusão criada para as referências da grande mídia.

O jogo de cenas, intercalando a fala da participante com a da apresentadora, e o registro das expressões visuais, feito independentemente de com quem está a voz, são os recursos utilizados para enfatizar a existência de duas pessoas no palco. Rompem, consequentemente, com a ideia de tempo presente (afinal, não há duas Patrícias num único momento real) para a construção do tempo do discurso (as personagens se comunicam dentro de uma cronologia criada exclusivamente pela narrativa).

O diálogo, por sua vez, tanto entre quem está na tela quanto com quem está em casa, é um fenômeno indispensável para que a narrativa se desenvolva outro fator comumente perceptível nos programas do SBT. Além disso, há ludicidade na construção da Máquina enquanto personagem, mesmo com todos cientes de que esta é uma metonímia para indicar todos os profissionais envolvidos na produção - talvez, portanto, possa-se considerar que esta é a figura de linguagem mais relevante para a obra.

Outras figuras de linguagem utilizadas são carregadas de intencionalidade e funcionam como recursos ativadores de sentimentos no público telespectador. 0 polissíndeto, por exemplo, sugere o entusiasmo da participante; a aférese, seguida da quebra de paralelismo, direciona a fala da personalidade midiática ao nível coloquial de linguagem; a analepse, por si só, assume o propósito de resgate do passado para gerar expectativa, no presente, de algo que será concretizado em um futuro próximo. 
As repetições são comumente demarcadas por epanodes e epizeuxes, que colaboram com a criação de uma atmosfera de euforia; já a anáfora, que geralmente ofereceria a sensação de acúmulo, tem o encargo, aqui, de restringir com o propósito vangloriar. A elipse, por sua vez, atua como transformador da modalidade linguística, deixando ao visual a missão de expressar a ideia omitida pelo verbal. Para intensificar o sentimento de dificuldade na missão a ser executada, a gradação em clímax se apresentou em companhia da hipérbole.

Notou-se ainda que o paradoxo ajuda na sensação de insegurança, passando ao público a dúvida de se a realização será bem-sucedida. De volta à hipérbole, ela cumpre outro papel ao se unir ao eufemismo, contribuindo para o destaque na transformação realizada. A antonomásia surge, nesse ponto, como uma tentativa de inferiorizar o "antes" e superiorizar o "depois". Por fim, é possível dizer que a filha de Silvio Santos entrou na Máquina e voltou a ser Patrícia Abravanel, com personalidade própria, mas respeitando o estilo sbtista de encenar.

\section{Referências}

BALLY, Charles. Traité de stylistique française. Paris: Klincksieck, 1909.

BAPTISTA, Luiza. Construção da Celebridade em Talent Shows: Estudo de Caso do Programa The $X$ Factor. In: CONGRESSO DE CIÊNCIAS DA COMUNICAÇÃO NA REGIÃO SUDESTE, 19., Vila Velha, 2014. Anais.... Vila Velha (ES): Intercom, 2014, p. 1-15. Disponível em: <https://goo.gl/awDWbb>. Acesso em: 21 nov. 2016.

BECHARA, Evanildo. Moderna gramática portuguesa. 37. ed. Rio de Janeiro: Nova Fronteira, 2009.

BORDWELL, David. Figuras traçadas na luz: a encenação no cinema. Trad. Maria Luiza Machado J atobá. Campinas: Papirus, 2008.

BUTLER, Jeremy G. Television style. Nova Iorque: Routledge, 2010.

FERNANDES, Wandreza. "Máquina da Fama" conquista décima vitória consecutiva sobre programa "Xuxa Meneghel". Área Vip, 2 fev. 2016. Disponível em: <http://goo.gl/2P1bVt>. Acesso em: 15 fev. 2016.

GARCIA, Othon M. Comunicação em prosa moderna: aprenda a escrever, aprendendo a pensar. 26. ed. Rio de Janeiro: FGV, 2007.

GUIRAUD, Pierre. A estilística. São Paulo: Mestre J ou, 1970.

HENRIQUES, Claudio Cezar. Estilística e discurso: estudos produtivos sobre texto e expressividade. Rio de Janeiro: Elsevier, 2011.

HERGESEL, João Paulo. Estilística aplicada à websérie. Saarbrücken (Alemanha): Novas Edições Acadêmicas, 2015.

KILPP, Suzana. Sentidos identitários de programação em TVs on-line. E-compós, Brasília, v. 18, n. 3, p. 1-17, set./dez. 2015. Disponível em: <http://goo.gl/xizhzk>. Acesso em: 15 fev. 2016. 
LAPA, Manuel Rodrigues. Estilística da Língua Portuguesa. 4. ed. São Paulo: Martins Fontes, 1998

MARTINS, Nilce Sant'Anna. Introdução à estilística: a expressividade na língua portuguesa. 4. ed. São Paulo: Edusp, 2008.

MARTINS, Rafael Barbosa Fialho. Resgate histórico das vinhetas do SBT: a busca por um "estilo sbtista". CoMtempo, São Paulo, v. 6, n. 2, p. 1-16, 2014. Disponível em: <http://goo.gl/FW4TOC>. Acesso em: 15 fev. 2016.

MATEUS, Suzana Maria de Sousa. Okay, ladies, now let's get in formation: o dia em que Beyoncé pautou questões raciais no Super Bowl 50. In: CONGRESSO DE CIÊNCIAS DA COMUNICAÇÃO NA REGIÃO NORDESTE, 18., Caruaru, 2016. Anais.... Caruaru (PE): Intercom, 2016, p. 1-15. Disponível em: <https://goo.gl/SAluUZ>. Acesso em: 21 nov. 2016.

MONTEIRO, José Lemos. A estilística: manual de análise e criação do estilo literário. Petrópolis: Vozes, 2005.

NOVAES, Anderson Lucas. A reprodução da música mercantil nos programas de covers: uma análise dos programas Astros (SBT) e Ídolos (Rede Record). Espaço Livre, v. 5, n. 9, p. 513, jan./jun. 2010. Disponível em: <https://goo.gl//ATm3W>. Acesso em: 21 nov. 2016.

PORTAL O Planeta TV. Máquina da Fama fecha o mês de janeiro na vice-liderança. Audiência da TV, 30 jan. 2014. Disponível em: <http://goo.gl/AIX9vY>. Acesso em: 16 fev. 2016.

ROCHA, Debora Cristine. Reality TV e reality show: ficção e realidade na televisão. Ecompós, Brasília, v. 12, n. 3, p. 1-16, set./dez. 2009. Disponível em: <https://goo.gl/akXmgf>. Acesso em: 21 nov. 2016.

ROCHA, Simone Maria. Estilo televisivo - e sua pertinência para a TV como prática cultural. Florianópolis: Insular, 2016.

SANTO, João Paulo Dell. Programas do SBT registram péssima audiência no sábado; “Máquina da Fama" estreia em baixa. RD1, 10 nov. 2013. Disponível em: <http://goo.gl/mfAahD>. Acesso em: 15 fev. 2016.

SOUSA, Silvia Maria de. Silvio Santos vem aí: programas de auditório do SBT numa perspectiva semiótica. Niterói: Editora da UFF, 2011.

SPITZER, Leo. Lingüística e historia literaria. 2. ed. Trad. José Perez Riesgo. Madrid: Gredos, 1968.

SUHAMY, Henri. As figuras de estilo. Porto (Portugal): Rés, 1994.

VANOYE, Francis; GOLIOT-LÉTÉ, Anne. Ensaio sobre a análise fílmica. 2. ed. Campinas: Papirus, 2002. 